in the United States and to reverse the escalating growth of tobacco-caused disease occurring in most other nations of the world.

The views expressed in this paper are those of the author and do not reflect an official position of the US federal government or its agencies.

1 US Centers for Disease Control and Prevention. Cigarett smoking among adults - United States, 1993. MMWR smoking among

2 Lynch BS, Bonnie RJ, eds. Growing up tobacco free Preventing nicotine addiction in children. Committee on preventing nicotine addiction in children and youths, Institute of Medicine. Washington, DC: Nationa Academy Press, 1994

3 US Department of Health and Human Services. Preventing tobacco use among young people: a report of the Surgeon General. Atlanta, Georgia: Public Health Service, Centers for Disease Control and Prevention, Office on Smoking and Health, 1994. (US Government Printing Office No S/N 017-001-00491-0.)

4 Peto R, Lopez AD, Boreham J, Thun M, Heath C. Mortality from smoking in developed countries 1950-2000. Mortality from smoking in developed countrie

5 US Centers for Disease Control and Prevention. Cigarette smoking-attributable mortality and years of potential lif lost - United States, 1990. MMWR 1993; 42: 645-9.

6 Schuh LM, Henningfield JE. Nicotine replacement treatment and public health interventions: toward a marriage of two approaches. In: Slama K, ed. Tobacco and health proceedings of the ninth world conference on tobacco and health (in press)

7 US Department of Health and Human Services. The health consequences of using smokeless tobacco. A report to the consequences of using smokeless tobacco. A report to the Maryland: Public Health Service, National Institutes of Health, 1986. (NIH Publication No 86-2874.)

8 Connolly GN, Winn DM, Hecht SS, Henningfield JE, Walker B, Hoffmann D. The reemergence of smokeless tobacco. N Engl f Med 1986; 314: 1020-7.

9 Slade J, Connolly GN, Davis RM, Douglas CE, Henning field JE, Hughes JR, et al. Report of the tobacco polic research study group on tobacco products. Tobacco Control 1992; 1 (suppl): S4-9.

10 US Department of Health and Human Services. The health consequences of smoking : nicotine addiction: A report of the Surgeon General, 1988. Rockville, Maryland: Public
Health Cervice, Centers for Disease Control, Office on Smoking and Health, 1988. (DHHS Publication No (CDC) 88-8406.

11 Henningfield JE, Stapleton JM, Benowitz NL, London ED. Higher levels of nicotine in arterial than in venous blood after cigarette smoking. Drug Alcohol Depend 1993; 33: 23-9.

12 Henningfield JE, Keenan RM. Nicotine delivery kinetics and abuse liability. $\mathcal{F}$ Consult Clin Psychol 1993; 61: 743-50.

13 Breslau N, Fenn N, Peterson EL. Early initiation and nicotine dependence in a cohort of young adults. Drug Alcohol Depend 1993; 33: 129-37.

14 Robins LN, Murphy GE. Drug use in a normal population of young negro men. Am $\mathcal{F}$ Public Health 1967; 57 : of young

15 Kandel DB. Issues of sequencing of adolescent drug use and other problem behaviors. Drugs Society 1989; 3: 55-76.

16 Giovino GA, Henningfield JE, Tomar SL, Escobedo LG, Slade J. Epidemiology of tobacco use and dependence. Epidemiol Rev 1995; 17: 48-65.

17 Kessler D. Nicotine addiction in young people. $N$ Engl Med 1995; 333: 186-9.

18 Henningfield JE. Nicotine addiction. In: Substance abuse. Ross roundtable on critical issues in family medicine. Columbus, OH: Ross Products Division, 1994: 171-86.

19 George $\mathrm{H}$. Gallup International Institute. Teen-age attitudes and behavior concerning tobacco. Princeton, NJ : tudes and behavior concerning tobacco. Princet

20 Henningfield JE, Kozlowski LT, Benowitz NL. A proposal to develop meaningful labeling for cigarettes. $\mathcal{F} A M A$ $1994 ; 272$ : 312-4.

21 Benowitz NL, Henningfield JE. Establishing a nicotine threshold for addiction. $N$ Engl F Med 1994; 331 : 123-4.

22 Hughes JR. An algorithm for smoking cessation. Arch Fam Med 1994; 3: 280-5.

23 Woody GE, McNicholas LF, Vocci F, Henningfield JE, and staff of pilot drug evaluation unit of Food and Drug Administration. Draft report to the US Food and Drug Administration. Draft report to the

24 Transdermal Nicotine Study Group. Transdermal nicotine for smoking cessation. Six-month results from two multicenter controlled clinical trials. $\mathscr{f} A M A 1991 ; 266$ : multice

25 Reuter P, MacCoun RJ. Lessons from the absence of harm reduction in American drug policy. Tobacco Control 1995; 4 (suppl 2): $\overline{\mathrm{S}} 28-32$

26 Goldstein A. Addiction: from biology to drug policy. New York: WH Freeman and Company, 1994.

27 Hughes JR. Applying harm reduction to smoking. Tobacco Control 1995; 4 (suppl 2): S33-8.

\title{
Lessons from the absence of harm reduction in American drug policy
}

\author{
Peter Reuter ${ }^{\star}$, Robert J MacCoun
}

\section{School of Public \\ Affairs and \\ Department of \\ Criminology \\ University of \\ Maryland, Van \\ Munching Hall, \\ College Park, \\ Maryland 20742, USA \\ P Reuter}

Graduate School of

Public Policy,

University of

California, 2607

Hearst Avenue,

Berkeley, California

94720-7320, USA

R J MacCoun

Correspondence to

P Reuter PhD

$\star$ Dr Reuter delivered this paper at the conference.
Even among its supporters, the American drug control strategy provides few grounds for enthusiasm. Despite many indications that the prevalence of drug use has declined over the past decade, in many ways the severity of the drug problem has remained fairly constant. ${ }^{1}$ Moreover, our current mix of policies is expensive, intrusive, and may actually contribute to drug related harm. ${ }^{2}$ Thus there is considerable interest - as documented by a steady stream of popular books, television programmes, and analytic and newspaper essays - in looking at a much wider array of drug control strategies, including approaches that go well beyond simply tinkering at the edges of existing programmes.

In this essay we shall provide a brief overview of one such alternative approach, the harm reduction paradigm. ${ }^{3-5}$ We shall discuss its influence in Western Europe and the barriers to its diffusion into American policy towards illicit drugs, and we shall offer a framework highlighting ways in which harm reduction might be integrated into the under- lying logic of American drug control. Finally we tentatively suggest its relevance to smoking policy.

\section{Drug policy and drug related harms}

The American "drug problem" is in fact constituted by quite a variegated list of harms. ${ }^{6}$ The table provides a partial listing intended to illustrate the diversity.

Some harmful effects are undoubtedly a direct function of drug use itself, and particularly of dependence. But much of the harm is attributable to the criminal distribution of drugs. Certainly the violence in drug selling and the development of a large criminal economy ${ }^{8}$ are functions of the conditions that we have created around drug selling, rather than any psychopharmacological characteristics of the drugs per se. It is not implausible that a prohibition on chocolate might lead to markets with potential for violence; such an inference is even more plausible with respect to cigarettes. Prohibition-related ill-effects are 
Elements of the drug problem

- Adolescents dropping ou

- Gateway to other problems

- High mortality among users

- Crime by users

- Creation of large criminal income

- Violence in distribution

- Distortion of source country societies

- Strains on US foreign policy

not limited to our own cities; our prohibition is what leads to production of cocaine and heroin in the Andes and Mexico, and the consequent violence and corruption associated with the drug traffic there. A legal market might well be supplied by efficient US agribusinesses.

The purpose of this list is simply to highlight the fact that American drug control strategies are themselves a gross source of some harmful drug effects. Accepting this proposition need not imply that the elimination of drug prohibition would yield a net reduction in social harm, a matter of considerable uncertainty. ${ }^{6,9,10}$ But it does suggest the need to take policy related ill-effects seriously, and to explore options for reducing them.

Consider, for example, why so much crime is involved in heroin use. Heroin, of course, is a narcotic; any violence associated with heroin markets is unlikely to reflect the drug's psychopharmocological effects. Rather, by prohibiting heroin and enforcing that prohibition aggressively, we have artificially made it and extremely ( $\$ 1000$ per pure gram), ${ }^{11}$ thus creating incentives for violent market activities.

One result of the high price of heroin is that we have few heroin users in this country. According to existing estimates - which are seriously flawed ${ }^{12}$ - there have been between half a million and a million heroin addicts for essentially a generation. Moreover, they have been the same individuals; the incidence rate of new heroin addicts has been extremely low throughout that period. A second result is that we have made heroin so expensive that those who use it spend much of their time in pursuit of the money to buy the drug.

Many of the ill-effects of drug use on health are also clearly related to policy. American heroin addicts generally inject heroin, rather than smoke it as in some other countries ${ }^{13}$; arguably, this is because prohibition has made heroin so expensive. Moreover, restrictions on needles and syringes may have been important in the development of drug-sharing markets and cultures in various cities, promoting the spread of AIDS.

There is no doubt then that prohibition and its implementation are responsible for some of the harm done by addictive drugs. Again, this does not prove that prohibition has failed. We may still be better off with these harmful effects than with the alternatives under legalisation; that is a complicated and separate question. But the fact that these visible illeffects are the result of policy has led us to inquire whether it may be possible to retain the general policy framework, but to make harm reducing changes in its implementation; to adapt a phrase from the Bush Administration, "a kinder, gentler prohibition". This raises the question of whether we might be able to trade reductions in ill-effects against reductions in use and profit by doing so.

Drug policy analysts and law enforcement agencies commonly make three assumptions about the dynamics of markets for dependency-creating and expensive drugs. We use heroin as an illustration. First, demand for heroin is inelastic, that is, raising the price of heroin by $10 \%$ reduces consumption by less than $10 \%$, resulting in an increase in total expenditure on the drug. Second, more stringent drug law enforcement raises heroin prices. Third, heroin users are dependent on crime to finance their heroin consumption. Although we have remarkably little direct evidence for the first two of these assumptions, they are consistent with economic theory and supported by many forms of indirect evidence. ${ }^{14}$ Collectively, they imply that tough enforcement against heroin markets will increase the crime related to heroin.

Of course, other harmful effects are involved, which may have different dynamics and sources. Moreover, our conclusions are firmer with respect to the short to medium term (especially concerning the elasticity of demand); if the long term elasticity is higher we may get a different result. But the analysis does raise the question as to what, from a social policy perspective, is the optimum price of heroin. The answer may be a lower price than we have right now, suggesting that we may have increased net harm by relying on tougher heroin enforcement over the past decade.

It is clear that the benefits and costs associated with the policy choices are distributed very differently among various parties, from neighbourhoods to family to users, an issue that is beyond the scope of this paper. But this line of thinking suggests that drug use and drug related harm should not always be seen as positively related in a simple, direct fashion. There may be circumstances under which we do not want to minimise drug use, if the programmes that minimise that use are themselves generators of social harm.

\section{Harm reduction in western Europe}

Such arguments may invite scorn among American politicians, but they have become fairly widely accepted in western Europe, mostly in response to AIDS $^{15}$ under the rubric of "harm reduction". In The Netherlands, it is clearly more than a slogan; the approach preceded AIDS and the government explicitly makes policy in a fairly sophisticated fashion on harm reduction grounds. The question asked of a policy is not what it does to prevalence, but explicitly how it affects the harms arising from drug use in the nation as a whole. Britain has also moved substantially in the direction of harm reduction, ${ }^{16}$ as have (in varying degrees) Denmark, Germany, and Switzerland. There are, however, substantial pockets of European resistance, most notably in Sweden, which is explicitly hostile to harm reduction.

Harm reduction tends to be formulated not 
in terms of broad "top down" policies, but rather as specific, localised programmes. Major examples include needle and syringe exchange, "zones of tolerance" where drug users can congregate with relative legal immunity, and safe use information campaigns. In essence, either explicitly or implicitly these programmes send a complex message: we view drugs as harmful; we discourage you from using them, and we are eager to help you quit if you've started; but if you will not stop using drugs, we can help you to use them less harmfully.

Few harm reduction programmes - with the notable exception of needle exchange-have been rigorously evaluated. ${ }^{5}$ We are listing them here simply as instances in which the harm reduction approach has been given a programmatic reality. But the lack of credible evaluation in some of these programmes may be one important factor in their relatively weak influence in American drug policy.

Methadone is, of course, the one harm reduction programme that has made an impact in the USA. Some might question our labelling it as such, but few still subscribe to the theory that methadone provides a "stepping stone" from addiction to abstinence; research suggests that voluntary abstinence rates are no lower than those associated with drug-free treatment which are distressingly low. ${ }^{17}$ If one defines the problem as opiate addiction and adheres very literally to the goal of use reduction, methadone maintenance sustains or even worsens the problem. This has been the basis for strong resistance in this country, particularly from African-American political leaders, who view methadone maintenance as a form of enslavement. ${ }^{18}$ Nevertheless, research does show that methadone maintenance reduces criminality, morbidity, and mortality and promotes greater assimilation into mainstream society. ${ }^{1920}$ Thus it seems appropriate to label it as a form of harm reduction.

There is growing interest in decriminalisation or legalisation in western Europe. ${ }^{10}$ This interest has many sources, but with respect to cannabis there is a sense that the harmful ellects that come from cannabis use are less than the harmful effects that come from stringent enforcement of prohibitions against use itself. Some forms of decriminalisation (minimal and non-incarcerative penalties for personal possession) have already been adopted in Italy and Spain, and are becoming the prevailing doctrine in Switzerland and Germany. But except for The Netherlands - a complicated case with respect to cannabis - no country has moved to legalisation; that is, no country permits legal manufacture and sale of cocaine, heroin, or other major street drugs. This need not imply any inconsistency; legalisation may reduce many drug related ill-effects, but many harm reduction advocates are agnostic or sceptical about the advisability of free market legalisation.

\section{American resistance to harm reduction} programmes

The USA has been largely immune to the harm reduction message. There is a certain amount of needle exchange activity in various American cities, much of it in a grey area of quasi-legal toleration by local authorities. The federal government is still bound by the Helms Amendment which says that no federal funding can be provided for syringe exchange programmes until the Centers for Disease Control and Prevention have released a report stating that there will be no increase in drug abuse as a result of needle exchange, and they has not yet done so (though many people claim they have in fact written such a report).

With the exception of methadone maintenance, which has different historical roots, the US government has aggressively resisted harm reduction, substituting instead a policy which is so widely accepted that it lacks an explicit name, though it might best be characterised as "use reduction". ${ }^{21}$ It is best illustrated by examining the National drug control strategy, which is published each year by the Office of National Drug Control Policy (ONDCP). Each year the Strategy includes an explicit list of goals for reducing various indicators of the prevalence and incidence of drug use. The numerical goals do not include harmful effects, for example the number of children born with complications resulting from maternal drug use, the number of overdose deaths, or the HIV seroincidence of intravenous drug users. ${ }^{22}$

Bureaucratic and political factors may partly account for this emphasis on use. First, there has been a notable separation between American drug policy and American AIDS policy, as illustrated by the difficulties faced by the national AIDS Commission in trying to increase the prominence of AIDS in the agenda of the ONDCP and other agencies at lower levels. Second, Congress required that ONDCP had to come up with measurable goals, arguably because the Democratic Congress did not trust a Republican administration. Now the situation has reversed, but the logic remains the same. Having measurable goals meant that ONDCP could not claim success after the fact; that they had to say in advance what they were going to do. Unfortunately, what was easily measurable was use. ${ }^{12}$ Harmful effects turned out to be very difficult to measure. So to some extent the demand to quantify progress may have helped to skew attitudes towards use and away from harm.

But this bureaucratic account may beg the question of why American drug policy places use reduction, grounded in a criminal justice or moralistic perspective, above harm reduction, which is grounded in a public health perspective. One argument is pragmatic. Clearly an argument can be made that if we reduce the number of users then we will reduce the ill-effects. This is indeed the argument of William Bennett, the first American "drug czar", in his introduction to the first National drug control strategy in 1989. But as we have already suggested, there can be a real tension 
between efforts to reduce drug use and efforts to reduce the harmful effects of drug use. By almost exclusively emphasising use reduction as an indirect means of reducing harm, we forgo opportunities of directly intervening to reduce harm, and we may even increase harm in the process.

Mr Califano's paper (in this issue, p. S19) may help to illustrate American resistance to harm reduction. He appears to associate harm reduction with legalisation and decriminalisation. Historically, there is some basis for this association. In the USA, the harm reduction message was first preached by the Drug Policy Foundation, which in its original incarnation was very much a legalisation institution. We believe that this origin remains an important influence in reducing the willingness to consider harm reduction arguments seriously.

A second factor may be that European harm reduction programmes have mostly been concerned with the welfare of the user. In the USA, drug related harm done to non-users (through crime and disorder) is given much greater prominence, though it is not apparent that existing harm reduction programmes offer a great deal in terms of reducing those costs borne by others.

A third factor is the general moralistic antagonism to hard drug users among US citizens. This partly stems from the strong association between drugs and street violence in American cities. Indeed, in America more than in Europe the two terms, drugs and crime, naturally flow together. It is much easier to see harshness as the appropriate response in the USA as compared to Europe, where to a much greater extent drugs are perceived as a behavioural and health problem rather than as a crime problem. ${ }^{23}$ Social distance may play a role here as well; arguably Americans were more tolerant of drug users in the 1970s, when the mass media's prototypical drug user was an Anglo-American college student.

\section{Use reduction and harm reduction: an} integrated perspective

Whatever its explanation, we believe that the strong American allegiance to use reduction will continue to pose an obstacle to harm reduction until harm reduction advocates begin to address concerns about levels of use explicitly. Thus we would like to offer an integrated perspective that might make harm reduction more palatable to "use reductionists" - at least those of the more pragmatic variety. We start with the largely overlooked truism that total drug related harm is the product of total use and average harm per incident of use. ${ }^{24}$ This is illustrated graphically in the figure.

To a considerable extent, existing harm reduction programmes have emphasised reductions in average harm to the individual user, or what might be called micro harm reduction. There has been little explicit discussion of aggregate harms. Americans often object that harm reduction "sends the wrong message"; one interpretation (there are others) is that efforts to reduce micro harm will actually increase total use. On the other hand, many Americans might argue that if we reduce total use, then even if harm per use increases, total harm (which is a product of the use incidence and the harm per use incidence) will decline. In essence, both of these arguments invoke the notion of macro harm reduction. But macro harm reduction is very much an empirical question, one that can only be addressed programme by programme, harm by harm. ${ }^{24}$

Some use reduction policies may indeed achieve macro harm reduction (primary prevention programmes are a plausible candidate), but others may yield modest effects on prevalence while actually increasing average harm substantially. Some micro harm reduction programmes may indeed achieve macro harm reduction (the evaluation evidence is favourable for needle exchange $\mathrm{e}^{5,25}$ ), but in theory, others might produce increases in prevalence that completely offset any reductions in average harm. (An example of the latter might be a programme to encourage heroin addicts to smoke their drug.) The issue is complicated by timing effects; interventions that reduce incidence at the cost of increasing the amount of harm per use may be harm reducing in the early stages of an epidemic but not in the late stages.

If use reduction advocates find this notion of macro harm reduction unpersuasive, a shift within use reduction from prevalence reduction to quantity reduction may provide a sort of halfway house, under the assumption that the ill-effects from drug use are heavily concentrated among heavy users. The fierce American opposition to the notion of "controlled drinking" among alcoholics does not bode well for quantity reduction as a political slogan.

\section{Conclusion: harm reduction and smoking}

The justification for presenting a paper on harm reduction in drug policy to a smoking cessation audience is the increasing recognition of the commonalties of problems presented by abusable substances, from heroin through alcohol to tobacco. Though we believe that tobacco control advocates can derive useful insights from harm reduction in drug policy, we do recognise three important differences between tobacco and the illicit drugs, each of which is at least partly a result of the differences in legal status.

First, the harm due to tobacco arises exclusively from the substance itself; it is not (as it is for illicit drugs) the consequence of policy. Those tobacco policies that are aimed at the delivery vehicle appear to play a harm reducing role. Second, the harmful effects of tobacco accrue primarily to users; passive exposure is the principal exception and even by the most generous estimates it accounts for a modest share of the total harm. Third, harm to nonusers mostly takes the form of indirect economic losses (payment for tobacco related diseases); there are almost no adverse conse- 


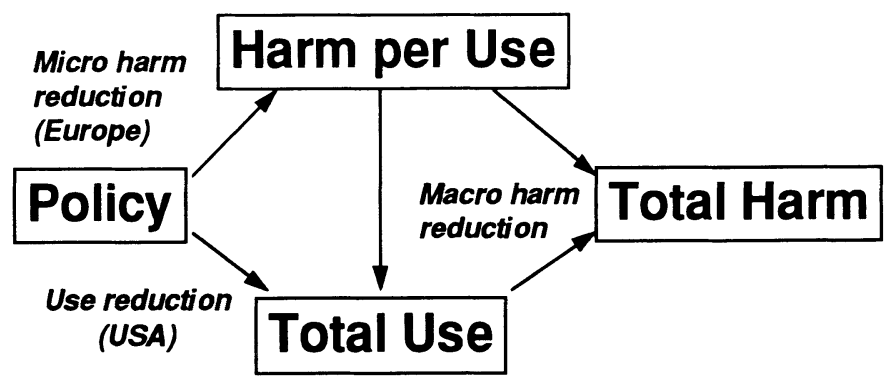

An integrated model of total harm reduction (adapted

from MacCoun Rf, Caulkins $\mathcal{F}$, in press)

quences arising from the behaviour of users. None of these statements would be true if tobacco were made illicit; some of these statements about tobacco might be true of marijuana if that smokable weed were made licit.

Harm reduction is very much a public health message. Indeed, it can seem little more than a truism to the public health community. Though the harm reduction label is of recent origin, the concept is by no means new to tobacco control. The lessons learned from attempts to reduce the harmfulness of tobacco without reducing prevalence are daunting for those of us who advocate harm reduction for illicits substances; consider the mixed record for filtered cigarettes and low tar cigarettes, and the explicit efforts to reduce consumption levels for smokers who either are unwilling or unable to achieve abstinence. But the lessons of the more moralistic approach to illicit drug control are at least as discouraging. It seems likely that optimal drug control requires a mixed strategy. However, if the behaviour being targeted is labelled as immoral, as is increasingly true of tobacco in American society, then the public health dimension of the tobacco control strategy may become harder to promulgate because it will be seen as bargaining with the devil. Maintaining the proper balance between stigmatising tobacco and reducing the harmfulness of its use is a delicate task.

The authors wish to thank Saul Shiffman for his extremely helpful suggestions.

1 Everingham SS, Rydell CP. Modelling the demand for cocaine. Santa Monica, CA: Rand, 199

2 Nadelmann E. Drug prohibition in the United States: costs, consequences, and alternatives. Science 1989; 245 : 939 47.

3 O'Hare P, Newcombe R, Matthews A, Buning EC, Drucke $\mathrm{E}$, eds. The reduction of drug related harm. London Routledge, 1991.

4 Heather N, Wodak A, Nadelmann E, O'Hare P, eds.
Psychoactive drugs and harm reduction: from faith to science. London: Whurr, 1993.

5 Des Jarlais DC, Friedman SR, Ward TP. Harm reduction: a public health response to the AIDS epidemic among injecting drug users. Annu Rev Public Health 1993; 14: 413-50.

6 Kleiman MAR. Against excess : drug policy for results. New York: Basic Books, 1992.

7 Goldstein P. The drugs/violence nexus: a tripartite conceptual framework. F Drug Issues 1986; 14: 493-506.

8 Saner H, MacCoun RJ, Reuter P. On the ubiquity of drug selling among youthful offenders in Washington, DC 1985-1991: age, period or cohort effect? f Quant Crimino (in press)

9 MacCoun RJ. Drugs and the law: a psychological analysi of drug prohibition. Psychol Bull 1993; 113: 497-512.

10 Reuter P, MacCoun RJ. Assessing the legalization debate. In: G Estievenart, ed. Policies and strategies to combat drugs in Europe. Amsterdam: Kluwer, 1995.

11 Drug Enforcement Administration. The illicit drug wholesale/retail price report. Washington, DC, various years.

12 Reuter P. Prevalence estimation and policy formation. $f$ Drug Issues 1993; 23: 167-84.

13 Leuw E. Drugs and drug policy in The Netherlands. In: Tonry M, ed. Crime and justice: an annual review of research, vol 14. Chicago, University of Chicago Press, 1991: 229-76

14 Boyum, D. Reflections on economic theory and drug enforcement. Unpublished $\mathrm{PhD}$ dissertation, Cambridge, Massachusetts: Kennedy School of Government, Harvard University, 1992.

15 MacCoun RJ, Model K, Phillips-Shockley H, Reuter P. Comparing drug policies in North America and Western Europe. In: G. Estievenart, ed. Policies and strategies to combat drugs in Europe. Amsterdam: Kluwer, 1995.

16 Advisory Council on the Misuse of Drugs. AIDS and drugs misuse. London: HMSO, 1987.

17 Maddux JF, Desmond DP. Methadone maintenance and recovery from opioid dependence. Am $\mathcal{F}$ Drug Alcohol Abuse 1992; 18: 63-74.

18 Lusane C. Pipe dream blues: racism and the war on drugs. Boston: South End Press, 1991

19 Ball JC, Ross, A. The effectiveness of methadone maintenance treatment. New York: Springer Verlag, 1991.

20 Hser Y, Anglin MD, Chou CP. Evaluation of drug abuse treatment: a repeated measures design assessing metha done maintenance. Evaluation Rev $1988 ; 12: 547-70$

21 MacCoun R, Reuter P, Kahan J, Saiger A. Drug policies and problems: the promise and pitfalls of cross-national comparisons. In: Heather N, Wodak A, Nadelmann E, Comparisons. In: Heather N, Wodak A, Nadelmann E,
O'Hare P, eds. Psychoactive drugs and harm reduction: from faith to science. London: Whurr Publishers, 1993 .

22 Reuter P, Caulkins J. Redefining the goals of drug policy: report of a working group. Am $\mathcal{F}$ Public Health 1995; 85: 1059-63.

23 Commission of the European Community. Eurobarometer public opinion in the European Community, vol 32, 1989.

24 MacCoun RJ, Caulkins J. Examining the behaviora assumptions of the national drug control strategy. In Bickel WK, DeGrandpre, RJ, eds. Drug policy and human nature: psychological perspectives on the prevention, management, and treatment of illicit drug use. New York: Plenum Press (in press).

25 Walters JK, Estilo MJ, Clark GL, Lorvick J. Syringe and needle exchange as HIV/AIDS prevention for injection drug users. $\mathcal{F} A M A$ 1994; 271 : 115-20. 